\title{
DO CONTATO DIRETO COM A ARTE, A CULTURA E A NATUREZA
}

\author{
ON THE DIRECT CONTACT WITH ART, CULTURE AND NATURE
}

\author{
Ana Beatriz de Paiva Costa Barroso \\ Doutora em Comunicação pela UNB. Docente do Programa de Pós-Graduação em Arte da UNB. \\ Programa de Pós-Graduação em Arte \\ Universidade de Brasília (UNB) \\ Brasília - DF - Brasil \\ Endereço: \\ Instituto de Artes \\ Campus Universitário Darcy Ribeiro \\ Brasília - DF \\ CEP: $70910-900$ \\ E-mail: \\ abeatrizb@gmail.com
}

RESUMO

Neste artigo apresento um processo de educação estética pautado no convívio diário com a arte, com a cultura e com a natureza. A arte é vista como uma pluralidade de manifestações ligadas a culturas próximas e distantes das pessoas que a experimentam. O reconhecimento dessa diversidade poética é um traço marcante e raro de educação estética na atualidade. A vivência dessa diversidade é o que nos permite adentrar no desconhecido, do outro e de nós mesmos. Abre-se, assim, a possibilidade para que a educação estética seja vista e percebida em sua potência eticamente transformadora.

PALAVRAS-CHAVE: Educação. Arte. Sensibilidade.

ABSTRACT

This article presents a process of aesthetic education based on daily contact with art, culture and nature. Art is seen as a plurality of manifestations linked to near and distant cultures of the peoples who experience them. The recognition of this poetical diversity is a striking and rare feature of aesthetic education today. The experience of this diversity is what allows us to step into the unknown of the otherness and of ourselves. Therefore, the possibility for aesthetic education is seen and perceived in its ethical transformative potential.

KEYWORDS: Education. Art. Sensibility.

O esteta Max Bense (2009), em visita ao Brasil nos anos 60, observou um traço curioso em nossa cultura. Segundo ele, o brasileiro aprende por contato. Nisso, ele seria diferente do europeu, que aprende de modo cartesiano. Desde que li essa observação, venho eu também observando como o contato direto e integral com aquilo que nos interessa nos é caro. Talvez sejamos, de maneira geral, um povo essencialmente sinestésico - em nós, os sentidos se juntam, tocamonos ao nos falar, pegamos no braço, no ombro, na mão de nossos interlocutores, referimo-nos ao paladar para expressar percepções que, a rigor, seriam apenas visuais, ou à audição para aludir a um aroma. Para o desenvolvimento de uma educação estética, esse traço cultural nos 
é extremamente favorável. Isso porque na educação estética o corpo, compreendido em sua integralidade de sensações e pensamentos, está em primeiro plano. É por ele e é nele que se operam transformações da ordem do sensível.

Pode até soar estranho que se fale no corpo como algo destacado de nós, mas há atualmente em operação um mecanismo cultural que provoca, sim, esse distanciamento. Seja porque o corpo já pareça obsoleto a alguns, seja porque seja esquecido, seja porque esteja negligenciado, seja porque anda junto com tantos aparatos tecnológicos que já é outro. A arte, como algo que se encontra pulverizado na cultura, teria condições de detectar esse distanciamento, hiato ou lacuna, entre o corpo e nós, de denunciá-lo ou enaltecê-lo, de fazer com que o percebamos e de agir no sentido de... não sabemos.

Não sabemos por que não há um sentido único de ação para a arte no momento atual. Dizer que a arte na contemporaneidade experimenta um pluralismo único é afirmar que não há um só sentido possível de ação e de compreensão, mas sim uma multiplicidade de sentidos e de valores em jogo, em interação. Essa afirmação por si mesma nega, realmente, o movimento de globalização da cultura. Tal negação não é absoluta, como se verá adiante; é relativa e constituise como uma forma de resistência. É exatamente a essa resistência que leva uma educação estética fundamentada na pessoa vista como um corpo culturalmente constituído, marcado pelas condições do meio em que habita, um corpo concreto, com necessidades e desejos múltiplos e variados, arduamente domesticado ao longo de gerações. Um corpo que carrega consigo, em suas mínimas partes, uma história.

De encantamento em encantamento, o povo amazônico vive a magia desta terra misteriosa, contrabalançando o real com o imaginário - que conta com a corroboração dos mais velhos, que reiteram convictamente a verdade dos mistérios das matas, dos rios, dos ares, sendo que muitos dariam a própria vida para jamais deixar de acreditar no sobrenatural que ouviram e "viram" desde a mais tenra idade, e em torno do qual foram embalados anos a fio, no remanso do segredo enigmático que só a eles, povo simples amazônida, foi revelado. (VIEIRA, 2010: 25).

Essa história, ou melhor, essas histórias, não devem ser varridas para baixo do tapete, não devem ser esquecidas como se não existissem, nem apagadas em prol de uma (pós) história maior e avassaladora, que sistematicamente ignora as partes que a constituem. Pois, por onde sentimos, onde se alojam nossas emoções se não em nós mesmos, naquilo que ouvimos e vemos com os olhos da nossa própria imaginação? Eventualmente temos a impressão que nos distanciamos tanto de nós mesmos e de nosso meio, que habitamos esferas tão abstratas e virtuais, que uma espécie de barreira invisível se ergue entre isso que chamamos de nós e isso que reconhecemos como não sendo nós. Outras vezes, são as pressões de nosso próprio íntimo que nos impedem de estar plenamente cônscios e, paradoxalmente, esquecidos de nós mesmos, plenamente vivos. Ainda que a incompletude - e não a plenitude - seja mais condizente conosco, com o próprio estar e ser vivo, eventualmente a sensação de mal-estar provocada pela cultura (FREUD, 2011), a qual já se alojou em nossas intimidades, é tão grande que impede a própria oscilação entre estados e experiências de plenitude e de insatisfação; paralisam, estancam. A arte não chega nesse momento com a pretensão de salvar a pessoa de tal estado. A arte não salva nem remedia. Não há redenção possível para a condição humana. Ou, se há, as religiões já se ocupam em proclamá-la. A arte, nesse caso, embora possa eventualmente servir como pharmacon, não se esgota nesse serviço.

Nessas tortuosas trilhas / a viola me redime / creia ilustre cavalheiro / contra fel moléstia crime / use Dorival Caymmi / vá de Jackson do Pandeiro / Vi cidades, vi dinheiro / bandoleiros, vi hospícios / moças feito passarinho / avoando de edifícios / fume Ari, cheire Vinícius / beba Nelson Cavaquinho / Para um coração mesquinho / contra a solidão agreste / Luiz Gonzaga é tiro certo / Pixinguinha é inconteste / tome Noel, Cartola, Orestes / Caetano e J oão Gilberto. (BUARQUE, ParaTodos, 1993).

A arte permanece sendo algo maior, que comporta múltiplos sentidos, que não se deixa usar, explicar nem apreender facilmente. Embora o deixe também. Como é, então, educar em arte? Antes de responder, mesmo que eu não pretenda responder - seria despropositado —, esclareço, aqui, a pequena diferença que existe entre pensar a educação estética e a educação em arte. A primeira é mais abrangente porque trabalha o aparato sensível da pessoa e por meio dele permite uma reflexão acerca do belo e da arte. A segunda se concentra na arte, embora não se negue a estabelecer relações com o belo. 
Cabe lembrar que, etimologicamente, aisthesis designa sensação. Um desdobramento possível para essa matriz semântica é a compreensão da estética como uma percepção essencialmente oriunda dos cinco sentidos básicos do corpo humano - audição, visão, paladar, olfato e tato. Classicamente, a Estética é uma disciplina filosófica voltada aos estudos acerca do belo e da arte. Contudo o belo estudado na Estética já não se restringe à noção clássica de belo e, conceitualmente, abre-se a outras categorias que tradicionalmente lhes eram distantes, como o grotesco, o feio, o risível (SUASSUNA, 2005). Penso que ambas a formas de educação, a estética e a em arte, com seus distintos enfoques, complementam-se. Buscarei neste texto construir um caminho favorável a esta complementaridade. O elo de união entre elas encontra-se no corpo, é a pessoa. A educação estética trabalha suas portas de entrada, seu aparato sensível, o que e como o corpo sente e lembra; a educação em arte trabalha suas saídas: o que e como este corpo produz arte.

Ainda há de se remarcar um detalhe. Quando se diz que a estética se ocupa do belo e da arte, geralmente se pensa na apreciação da arte, na reflexão sobre a arte já existente, já reconhecida como arte. A educação em arte se distingue nesse sentido por se ocupar justamente da criação de arte, com todos os riscos que essa criação comporta. A educação em arte adentra, então, forçosamente, o reino da linguagem, já que é por meio desta que se torna possível criar arte. Não se trata aqui da linguagem articulada, da língua ela mesma, mas da linguagem artística com a qual se cria - dança, música, cinema, poesia, pintura, videoarte, performance, instalação, gravura, etc. Abordarei esses dois lados procurando rememorar meu próprio processo de educação estética e artística.

\section{DO FREQUENTAR FORMAS DE ARTE}

É no dia a dia que me alimento de arte. Não concebo uma educação estética que se prive dessa nutrição diária. Isso porque, efetivamente, não há ninguém melhor que os próprios artistas para nos educar em arte. Percebo isso muito claramente, por exemplo, em uma disciplina que ministro na graduação do curso de Artes Visuais: fundamentos de linguagem. Ainda que seja necessário percorrer um programa que transite por algumas abordagens teóricas, notadamente a semiótica e a história, a fim de especular sobre as origens da linguagem, perceber sua indissociabilidade das noções de humano e de cultura e compreender as reverberações do signo (não só linguístico) na construção de relações que tenham ou façam sentido, o que me parece mais fundamental ao entendimento da linguagem se encontra em versos, em prosas, em fragmentos de poesias, de romances, canções e filmes. Nesse material o conhecimento que procuro me chega de modo integral e tenho a sensação de não só entender, mas de poder, eu mesma, criar. Novamente, é o corpo todo que sente, percebe e conhece, que altera-se, estilhaça-se, perde-se no todo e se reinventa.

Falando de Carlos Fuentes, O. Paz faz um interessante paralelo entre o estilo deste escritor e o lugar que o corpo ocupa em sua obra. Trata-se de um estilo feito de "estilhaçamento contínuo", de justaposições e de combinações; um estilo dominado pelo fluxo e pela circulação. Ao mesmo tempo, "o corpo ocupa um lugar central, a sede, a urgência sexual... as sensações mais imediatas e diretas... as combinações do desejo e da imaginação, os desvarios e as alucinações dos sentidos... a paixão erótica é cardeal". Podemos fazer uma leitura metafórica dessa análise literária e dizer que o erotismo possui algo de bruto, de terreno, que retorna à natureza primordial, originada da mistura de elementos diversos. O erótico, assim como a natureza, é uma combinatória em que o individual se perde na fusão universal. O estilhaçamento contínuo é um fato do corpo e, por isso mesmo, inscreve-se numa realidade que o excede. (MAFFESOLI, 2005: 88).

O distanciamento que normalmente a teoria estabelece com o objeto de estudo é, na arte (literária, visual ou em qualquer outra), burlado. O poeta e o artista nos colocam, corporeamente, eroticamente, no coração da questão tratada. Talvez a razão para isso recaia no fato de que ao artista e ao educando em arte importe mais a fusão, a síntese, que a análise, uma vez em que a arte junta coisas naturalmente dispersas, funde, confunde e cria relações entre elementos aparentemente distantes.

Além disso, ideias filosóficas e científicas em forma de arte tocam-nos especialmente por trazerem imagens concretas (ou brutas) daquilo que, de outro modo, permaneceria no plano abstrato. Nesse sentido, possuem erotismo. Quando digo imagens concretas, penso em imagens em ação, imagens que são trabalhadas em detalhe, em que cada detalhe se liga ao todo, à imagem total (abstrata) resultante da relação entre as partes. Pois, cabe lembrar, em estética o que conta 
é a percepção do todo e não das partes isoladas que compõem o todo. Longe de se configurarem como meras ilustrações das ideias, as imagens dinamizadas na arte configuram-se como um campo de experimentação ímpar, tanto para o artista quanto para o fruidor, tanto para o escritor quanto para o leitor. A arte como experiência (DEWEY, 2005) pode então ser vivenciada nesse duplo posicionamento; um não exclui o outro, pelo contrário, um complementa o outro.

Já que falei em vivência, cumpre derivar daí uma noção que considero essencial para a educação de um modo geral e para a educação estética de um modo particular. Trata-se da noção de convivência. Ora, se o ser humano se constitui como humano na convivência, pois é no conviver que emerge a linguagem articulada (MATURANA, 2010), nada mais intrínseco à geração de cultura e ao processo de educação, desde o núcleo familiar, passando pela dimensão comunitária e chegando ao espaço social, que a convivência. É nela que se opera a educação. Esse ponto, tão simples e ao mesmo tempo tão complexo - educar é conviver - , não pode ser esquecido, penso eu, sob o risco de nos perdermos em complicações desnecessárias e avassaladoras ao processo educacional. Quando nos voltamos para os desdobramentos desse processo no campo da estética (e da arte), perceber a educação como convivência se torna ainda mais necessário, já que é dessa convivência que brota a experiência.

\title{
DO ENTREGAR-SE À SUBSTÂNCIA DA ARTE
}

\begin{abstract}
Prazer comunicado é arte. O que significa a linguagem dos gestos: é a linguagem por meio de símbolos inteligíveis universalmente, formas de movimentos reflexos. O olho conclui imediatamente o estado que produz os gestos. Assim é com os sons instintivos. O ouvido conclui instintivamente. Esses sons são símbolos. (NIETZSCHE, 2005: 43).
\end{abstract}

Se "prazer comunicado é arte" sentir essa comunicação também o é. A arte está nos dois polos básicos da comunicação (emissor e receptor) e no meio, entre eles, entre o que é dito, feito, mostrado, dançado, cantado, ouvido e o que é recebido como tal. Talvez até a arte não esteja nem mesmo no meio, talvez esteja apenas em fluxo, num fluxo tão imperceptível e invisível, que dele só percebemos os vestígios, os restos, a sobra que fica. Por isso se colocar em contato direto com isso (tanto com o inapreensível quanto com seus resquícios) faz-se fundamental à educação estética.

Contato direto aqui não elimina o contato intermediado. A noção de contato direto que proponho não exige a presença física imediata do objeto ou obra de arte. Isso restringiria muito o campo de possibilidades de educação estética, pois no mundo contemporâneo já estamos acostumados a uma série de manifestações da arte que nos chegam intermediadas por inúmeros meios de comunicação. Isso não representa impedimento. Pelo contrário, abre-nos um leque considerável de oportunidades de conhecimento. O sentido de contato direto, aqui, recai sobre a ideia da constância. É preciso frequentar assiduamente a arte, os poetas, os artistas (suas biografias, ainda que romanceadas), ouvir música, assistir a filmes, folhear e ler livros de arte, de fotografia, tanto quanto ir a exposições, a teatro, a espetáculos musicais, assistir a programas de entrevista na televisão, não ter preconceito quanto a qualquer um dos meios, seja a televisão, o rádio, a Internet, em todos eles se podem encontrar formas de arte ou ecos da arte. Se a arte não é nada que se possa definir com precisão, se a arte é, essencialmente, um mistério, não podemos dizer com certeza onde ela está, nem que ela absolutamente não pode estar em qualquer lugar que seja - na telenovela, no bar da esquina, na camiseta estampada. Não ressuscitemos a velha dicotomia da alta e da baixa cultura e todo o universo de preconceitos que ela acarreta (ECO, 1970). É na convivência direta com a arte (o que quer que ela seja, como quer que a entendamos ou não entendamos) que vamos nos deixar transformar.

Quando digo que vamos nos deixar transformar não significa que vamos alterar nossa maneira de pensar. A estética provoca realmente uma alteração no ser como um todo e não só em sua maneira de pensar. Muitas vezes a mudança no pensamento vem arrastada pela transformação na sensibilidade. Esta, sim, concerne à estética. Esta, sim, é educada no contato direto com a arte. As duas instâncias não são separadas; sensibilidade e intelecto, sentimento e pensamento, ao contrário, andam juntos, amalgamados. Culturalmente, fomos nos habituando a separá-los e a vê-los como círculos independentes. Hoje já se sabe que não é assim. Hoje se fala com tranquilidade em razão sensível e em complexidade. Nenhuma das formas de arte é desprovida de razão, de ordem, de uma linguagem organizadora. 
Ao complexificar-se, a ideia de ordem se relativiza. A ordem não é absoluta, substancial, incondicional e eterna, mas relacional e relativa; depende de suas condições de surgimento, existência, e se reproduzirá incessantemente: toda ordem, cósmica, biológica etc., tem data de nascimento e, cedo ou tarde, terá data de falecimento. [...] O que é verdadeiramente pertubador para o reino determinista e para os cultuadores incondicionais da fossilização da linguagem, é que a complexidade de um objeto qualquer remete a uma região do devir não redutível a nunhuma lógica, qualquer que seja ela. (MORIN, 2009: 48).

O que é diferente na arte (em relação a outras formas de manifestação do pensamento) é que nela o sentimento, a vontade, o desejo, a loucura, o ilimitado, o desconhecido, o estranho e o complexo manifestam-se de modo a revigorar e a transformar quem a faz. Reforçando o que se disse mais acima, quem faz arte, nessa perspectiva, não é só o artista que cria a forma, mas também o fruidor, o espectador, o leitor, o ouvinte, o participante, o interator, que penetra na substância comunicada (de modo perturbador, extremamente harmônico ou arrebatador) na arte.

Como se educar esteticamente, para essa criação, senão vivenciando a arte em suas mais diversas formas e manifestações, aprendendo consigo mesmo a discernir gradações de beleza, sem preconceitos de meios (mídia), de linguagem, de materiais? Não há outro modo se não se lançar à arte, deixar-se arrebatar, abrir-se ao inusitado do sentimento, das sensações que uma obra lhe causa, perder-se nela. Voltar, daí, outro, completamente outro. Não só na maneira de ver o mundo, mas, sobretudo, no estar no mundo, no sentir o mundo. Quando isso acontece, e isso deve acontecer com certa constância e frequência, há educação estética: a pessoa se transforma e se renova como sujeito capaz de perceber o mundo como uma novidade, capaz de perceber que o mundo não é algo dado, fechado e acabado, mas algo em constante criação, aberto, por sua vez, ao que ele, sujeito, é capaz de, nele, inventar. A pessoa se sente e se faz criadora; a pessoa revitaliza sua dignidade de pessoa, de ser humano, ao revigorar-se como sujeito - insubordinado, não sujeitado.

O sujeito, esta invenção da modernidade (FOUCAULT, 2010), é aquele que pode decidir, que faz escolhas, que opta. Isso só é possível se há (isto é, se a pessoa tem ou conquista) vontade, desejo e se, a partir do desejo, vislumbra um leque de possibilidades de ação. A liberdade, nesse sentido, está na percepção desse conjunto de possibilidades de ação, na intuição do que pode advir como consequência da ação e na escolha por outra maneira de agir. Ora, estando sensibilizada e atenta, estando em transformação, sentindo-se em fluxo, a pessoa (o sujeito) torna-se capaz se escolher, de decidir, de conquistar o que quer que seja de acordo com a situação (o que ele/ ela percebe em um dado contexto) e em consonância com a sua vontade. O agir se processa, assim, de modo responsável e, realmente pessoal, digno.

\section{DA CULTURA}

Paralelamente ao contato direto com a arte, parece-me crucial compreender a cultura, vivê-la em sua plenitude. Além do entendimento corriqueiro que temos dela, como conjunto de hábitos, costumes, saberes, práticas sociais e valores partilhados entre os membros de uma comunidade (família, cidade, nação), a cultura também é um processo de interação com o outro. Assim a entendo. Nesse sentido, manter um contato direto com a cultura implica estar atento àquilo que rege nosso comportamento na lida com o outro, como agimos e reagimos, por que algo nos toca, fere-nos ou encanta. Quando viajamos e colocamo-nos em contato com uma cultura distinta da que nos é familiar, somos capazes de perceber isso com muita clareza: em tal lugar não se pode perguntar isso ou aquilo, porque as pessoas se ofendem, evite comentar isso ou aquilo para não ser indelicado. Em outras palavras, a cultura de certo modo molda nossa sensibilidade.

Ora, se queremos nos tornar e nos realizar plenamente como sujeitos (pessoas que fazem escolhas de modo deliberado e refletido) é importante perceber esse molde que, a rigor, não se constitui como uma escolha, pois nos é imposto, é algo circunstancial. Eventualmente esse molde nos incomoda, exclui-nos de certos círculos afetivos, não nos identificamos com ele. Muitas vezes, é a partir desse estranhamento, desse desajuste, que começamos a perceber a cultura, a nossa própria cultura. Começamos a percebê-la e a nos destacarmos dela, isolando-nos. Muitas vezes, é aí que a arte começa, nesse hiato, nesse abismo, nessa dificuldade de comunicação e de entendimento entre a pessoa e os seus. Outras vezes, essa percepção (da própria cultura) é carregada de encantamento e de entusiasmo. A pessoa se sente representante de sua coletividade, sente-se porta-voz de sua cultura, repara nela seus aspectos primordiais. 
Toda cultura, cabe lembrar, comporta um número expressivo de tradições. Estas constituemse como um conjunto de saberes e de ensinamentos adquiridos pela experiência de vida dos mais velhos e são transmitidos pela convivência. As tradições têm valor inestimável, com elas temos a sensação de não estar começando do zero. Elas nos instruem quanto a uma série de coisas já sabidas e experimentadas, ajudando-nos a nos colocar no mesmo compasso de nossos contemporâneos. No entanto não se pode confundi-la com a totalidade do que é preciso saber. Pelo contrário, junto a ela existe um universo desconhecido, de coisas não vistas nem vividas pelos mais velhos, um universo a ser conhecido, desvendado e inventado por nós e por cada pessoa que queira se fazer sujeito.

Eis aí o caráter libertário da educação estética. Ao nos alertar para nosso aparato sensível, ao nos despertar para a honestidade com que devemos nos tratar, para a necessidade do cuidado consigo, a educação estética nos leva a estender essa relação verdadeira, seja ela conflituosa ou harmônica, para com o outro, para com a cultura na qual nos inserimos. A transformação, radical ou discreta, opera-se aí, nessa relação. Tal relação só se efetiva em sua prática diária. O ser estético não é alguém que se esquiva de sua cultura, porque esta fere sua sensibilidade, tampouco alguém que elogia cegamente sua cultura sem aperceber-Ihe os limites e os preconceitos que ela engendra, mas alguém que, conscientemente inserido em um contexto cultural, com ele interage, a fim de saber mais e mais, sobre aqueles costumes, aquela visão de mundo, aquele universo de sensibilidades, aquele conjunto de valores e os modos de vivência e de sobrevivência que este todo permite e possibilita.

Neste ponto, algo quero dizer sobre a arte contemporânea e sobre as outras artes. Não definirei aquela. Aponto sucintamente, com o trecho abaixo, a dificuldade que ela representa para grande parte de nós, contemporâneos, eu inclusive.

O público, confrontado com a dispersão dos locais de cultura, com a diversidade da 'obras' apresentadas e seu número sempre crescente, com o número também crescente de revistas, jornais, anúncios, atraído por cartazes, atirado de um lado para o outro por críticos de arte, acumulando catálogos, parece desnorteado diante da arte contemporânea: é o mínimo que se pode dizer. (CAUQUELIN, 2005: 9).

Volta e meia vou a exposições temáticas, ligadas a culturas específicas de determinada época em determinado país ou continente - Índia, China, Rússia, Japão, África. Percebo, nessas experiências, como a arte tradicional, digamos assim, é arraigada à sua cultura de origem. Isso faz com que, por meio das obras expostas, percebamos essa cultura, modos de vida, valores, a visão de mundo compartilhada por aquelas pessoas. Já nas exposições de arte contemporânea, o que vemos geralmente é a visão de mundo, os valores, a intimidade ou a sensibilidade de um indivíduo e de sua cultura pessoal, como se esta estivesse destacada de seu contexto ou como se esse contexto pouco importasse. O delírio, as lágrimas, o riso, a dor ou o prazer da pessoa é o que está em jogo. Não sei, rigorosamente, o que isso significa, mesmo porque a arte contemporânea não é uma coisa única, que pode ser percebida em bloco, nem é algo sobre o que se tenha clareza do que seja e do que represente. Tampouco a arte contemporânea se resume ao que pode ser apreciado em forma de exposição. Sabe-se que a arte, na contemporaneidade, encontra-se, além do cubo branco, em ruas, rodoviárias, praias, muros, mares, campos e praças. Por isso, apenas observo que, no tocante à cultura, a arte contemporânea exige de nós outra expectativa: ela dificilmente se faz chave para a entrada em outra dimensão cultural, como acontece com as artes de outros tempos. Não há problema nisso. Pode ser que ela não seja chave, nem queira ser chave. Pode ser, e em alguns casos é, já provei, que ela seja e se constitua como relação, faça-se nexo, ponte e não chave, e nisso encontre sua beleza.

Isso se deve, talvez, ao fato de estarmos muito juntos a ela e termos dificuldade de vê-la em destaque, ou ao fato de haver realmente um achatamento (uniformidade ou universalidade) cultural que faz com que a arte contemporânea da índia não seja muito diferente da do Japão, nem da brasileira, nem da europeia, nem da Indonésia. Isso seria um indício significativo de que a globalização cultural é uma realidade e acompanha a globalização econômica? A ideia de sujeito global não estaria sendo concretizada (deformada) na de cidadão global? E quem é esse cidadão global? Peço desculpas pela longa citação que segue, mas ela me parece relevante nesse contexto, quanto mais porque quase sempre, ao se falar em educação estética e artística, e mesmo em educação de um modo geral, fala-se em cidadania.

Num artigo para a revista Newsweek, Emily Flynn Vencat e Gianne Brownell relatam como hoje em dia "o fenômeno do "só para sócios" está explodindo num novo estilo de vida que abrange 
tudo, desde relações bancárias privativas até clínicas que só aceitam pacientes convidados [...] cada vez mais, aqueles que têm dinheiro trancam sua vida a sete chaves. Em vez de comparecer a eventos com grande cobertura midiática, contratam espetáculos, desfiles de moda e exposições particulares de arte em casa. Compram fora do horário comercial e mandam investigar a classe social e o patrimônio de vizinhos (e possíveis amigos).' Portanto, uma nova classe global vem surgindo, "com, digamos, passaporte indiano, castelo na Escócia, apartamento em Manhattan e ilha particular no Caribe". O paradoxo é que os membros dessa classe global "jantam privativamente, veem obras de arte privativamente, tudo é privativo, privativo, privativo." Criam assim um mundo-vida só seu para resolver um problema hermenêutico angustiante; como explica Todd Millay, "as famílias ricas não podem apenas 'convidar os outros e esperar que entendam o que é ter 300 milhões de dólares'”. Então, quais são seus contatos com o mundo em geral? São de dois tipos: negócios e filantropia (proteger o meio ambiente, combater doenças, apoiar as artes etc). Esses cidadãos globais vivem em geral na natureza mais pura, seja caminhando na Patagônia, seja nadando nas águas translúcidas de ilhas particulares. (ZIZEK, 2011: 17).

Boa parte da arte contemporânea seria, na realidade, uma espécie de arte capitalista descartável, privativa, inacessível, distintiva, asseguradora e excludente. E os sonhos da diversidade cultural, da força da diferença, da riqueza do multiculturalismo? E a potência do medo, do duvidoso e do incerto? Há aqui uma equação a ser resolvida. Por outro lado, há a convicção de que, se aquela espécie de arte contemporânea é incontornável, ela não traduz a totalidade da arte e de que, se há uma dimensão dessa arte a ser trabalhada no âmbito da educação estética, ela talvez se encontre o extremo oposto do que é vivenciado como arte pelos ditos cidadãos globais.

DO CONTATO COM A NATUREZA

Por fim, o contato direto com a natureza nos permite entrar em sintonia com uma essência em nós anterior a nós, original, primitiva ou primeva, mais recôndita e selvagem que a segunda natureza, aculturada, de nós mesmos. Talvez esse contato seja um exercício de escuta, de silêncio, de ensimesmamento, de sentir. Desse contato surgiria um processo de educação estética fundamental, a educação de si por si mesmo, como indica Rancière (2004). Não me demorarei neste ponto porque não se pode falar dele para alguém, tão íntimo ele é. Também, se a ideia é que cada um eduque-se a si mesmo, ninguém pode fazer isso no lugar do outro ou para o outro. Essa é a parte que incomoda a alguns: a responsabilidade da educação estética em sua dimensão primordial é da pessoa ela mesma e não concerne a ninguém mais. Mal acostumados que estamos, a delegar que cuidem de nós, que façam por nós, que sintam por nós, nesse mundo em que a terceirização de inúmeros aspectos da vida pessoal tornou-se uma constante, recuperar a responsabilidade pelo seu próprio processo de constituição, pelo seu próprio vir-a-ser, pela sua própria educação estética pode apavorar. Mas não há como ser diferente: essa educação não é algo fechado, um pacote que possa ser vendido ou comprado; é uma conquista, um processo sobre o qual temos algumas pistas e vestígios dispersos; não é uma estrada já construída a ser trilhada por aventureiros orgulhosos ou esforçados. É coisa de nômade mesmo, de andarilho, de gente estranha, anormal.

Por isso, apenas assinalo aqui a necessidade desse contato íntimo com o tempo e com o espaço; com o clima e com a lentidão; com a velocidade e com o assustador; com as plantas; as montanhas; os lagos; as árvores; as nuvens; os oceanos; os monstros; as criaturas sombrias; os rios; as pedras; os insetos e animais, domésticos ou não. Boa parte do discurso ecologista rui ante tal contato, porque nele percebemo-nos, não como possíveis redentores ou carrascos, catastróficos, apocalípticos ou integrados, mas como mera parte dessa coisa maior - a natureza. Contraditórios como ela, mansos e medonhos, perfeitos e incompletos, caminhamos a esmo, a encontrar belezas e artes que se evaporam por nossos próprios poros.

REFERÊNCIAS

BENSE, Max. Inteligência brasileira: uma reflexão cartesiana. São Paulo: Cosac Naif, 2009.

BUARQUe, Chico. ParaTodos. Rio de Janeiro: Cia dos Técnicos. 1993. 1CD.

CAUQUELIN, Anne. Arte contemporânea. São Paulo: Martins, 2005. 
CONTRAPONTOS

DEWEY, J ohn. Art as experience. Berkley Publishing: 2005.

ECO, Umberto. Apocalípticos e integrados. São Paulo: Perspectiva, 1970.

FOUCAULT, Michel. A hermenêutica do sujeito. São Paulo: Martins Fontes, 2010.

FREUD, Sigmund. O mal-estar na cultura. Porto Alegre: L\&PM, 2011.

MAFFESOLI, Michel. A sombra de Dionísio: contribuição a uma sociologia da orgia. São Paulo: Zouk, 2005.

MATURANA, Humberto. Emoções e Linguagem na Educação e na Política. Belo Horizonte: Editora UFMG, 2009.

MORIN, Edgar. Educar na era planetária: o pensamento complexo como método de aprendizagem pelo erro e incerteza humana. 3. ed. São Paulo, SP: Cortez: UNESCO, 2009.

NIETZSCHE, Friedrich. A visão dionisíaca do mundo. São Paulo : Martisn Fontes, 2005.

RANCIÈRE, Jacques. O mestre ignorante. São Paulo: Autêntica, 2004.

SUASSUNA, Ariano. I niciação à Estética. Rio de Janeiro: J osé Olympio, 2005.

VIEIRA, Edithe Carvalho. Amazônia: contos, lendas, ritos e mitos. Brasília: Queen Elisabeth Projecto Editorial, 2010.

ZIZEK, Slavoj. Primeiro como tragédia, depois como farsa. São Paulo: Boitempo, 2011.

Artigo recebido em $01 / 08 / 2012$

Aprovado em 04/09/2012 